\title{
Swot Analysis At PT. Pegadaian (Persero) Branch Of Wiyung Surabaya
}

\author{
Rendy Suciana and Elok Damayanti \\ Program Studi Manajemen Fakultas Ekonomi dan Bisnis \\ Universitas Narotama Surabaya \\ Email author: elok.damayanti@narotama.ac.id
}

\begin{abstract}
This study aims to explore PT Pegadaian (Persero) Branch Wiyung Surabaya using qualitative research methods. The development at PT Pegadaian is increasingly progressing, but this should not make it less competitive with other competitors. Many things must be addressed at PT Pegadaian, one of which is by providing and providing the best quality service to its customers, therefore it requires strategic management to compete with other pawning services. So to determine the strategy used, the researcher uses a SWOT analysis, namely the steps through a matrix approach, identification of the external and internal environment, EFAS and IFAS analysis, determining the score so that the formulation of the competitive strategy will be found. The results of the SWOT analysis will find strengths, weaknesses, opportunities, and threats to PT Pegadaian (Persero) Surabaya.
\end{abstract}

\section{Keyword:}

SWOT, EFAS, IFAS

\section{Pendahuluan}

\subsection{Latar Belakang}

PT Pegadaian (Persero) menyadari tantangan ke depan semakin berat, sehingga perusahaan harus fokus untuk memenuhi hak nasabah dengan memberikan pelayanan yang terbaik. Dengan persaingan yang begitu ketat saat ini, kualitas jasa mempunyai peranan yang sangat berpengaruh dalam pengembangan jasa pegadaian. Mempertahankan konsumen menjadi hal yang sangat penting bagi perusahaan jasa khususnya. Membuat nasabah tetap loyal adalah senjata utama yang harus dilakukan oleh suatu PT Pegadaian (persero) dan harus bisa menciptakan loyalty tidak cukup hanya satisfaction karena kepuasan bukanlah tujuan akhir. Perusahaan sebaiknya tidak boleh berhenti apabila telah memberikan kepuasan kepada nasabahnya, tetapi harus berupaya bagaimana menciptakan agar nasabah tersebut tidak berpindah ke perusahaan lain dan nasabah menjadi semakin loyal.

PT Pegadaian (persero) adalah sebuah Badan Usaha Milik Negara di indonesia yang usaha intinya bergerak dalam bidang jasa penyaluran kredit kepada masyarakat atau hukum gadai. Oleh karena itu PT Pegadaian (persero) diharapkan dapat memiliki sumber daya yang berkualitas, baik sumber daya manusia maupun sumber daya bukan manusia. Dalam rangka meningkatkan kualitas sumber daya manusia dan untuk meningkatkan motivasi serta mengupayakan profesionalisme PT Pegadaian (persero) telah melakukan berbagai macam program intern dan ekstern baik pendidikan karir, pendidikan profesi, keterampilan serta berbagai kursus, latihan, penataran, seminar, lokakarya dan pelatihan manajemen dan teknis yang disesuaikan dengan kebutuhan PT Pegadaian (persero) guna meningkatkan kualitas tenaga kerja agar sesuai dengan kebutuhan perusahaan yang belum efektif. Oeh karena itu penulis tertarik melakukan penelitian berjudul " ANALISIS SWOT PADA PT PEGADAIAN (persero) CABANG WIYUNG SURABAYA“.

\subsection{Perumusan Masalah} diteliti:

Dari uraian yang terdapat pada latar belakang diatas, maka penulis mengidentifikasi masalah yang akan

1. Bagaimana peta analisis SWOT pada PT Pegadaian (persero) Cabang Wiyung Surabaya?

2. Strategi apa saja yang bisa dirumuskan dari hasil analisis SWOT pada PT Pegadaian (persero) Cabang Wiyung Surabaya?

\subsection{Tujuan Penelitian}

Tujuan dilakukannya penelitian ini adalah untuk mengetahui pengaruh:

1. Untuk memetakan analisis SWOT pada PT Pegadaian (persero) Cabang Wiyung Surabaya

2. Merumuskan strategi bersaing berdasarkan analisis SWOT pada PT Pegadaian (persero) Cabang Wiyung Surabaya 


\section{Tinjauan Pustaka \\ 2.1 PenelitianTerdahulu}

Tabel 1. Penelitian Terdahulu

\begin{tabular}{|c|c|c|c|}
\hline No & Judul & Hasil Penelitian & Perbedaan \\
\hline 1. & $\begin{array}{l}\text { Analisis SWOT pada Bank } \\
\text { Bukopin Syariah } \\
\text { Cabang Surabaya Laily Arifah } \\
(2008)\end{array}$ & $\begin{array}{c}\text { Megetahui faktor internal dan } \\
\text { eksternal pada Bank Bukopin } \\
\text { Syariah Cabang Surabaya }\end{array}$ & $\begin{array}{c}\text { Objek penelitian di bidang } \\
\text { kelembagaan pada Bank Bukopin } \\
\text { Syariah }\end{array}$ \\
\hline 2. & $\begin{array}{l}\text { Analisis SWOT pada PT Bank } \\
\text { Negara Indonesia (Persero) } \\
\text { Tbk Kantor Cabang Syariah } \\
\text { Medan, Almukaromah Rambe } \\
\text { (2007) }\end{array}$ & $\begin{array}{l}\text { Melakukan strategi yang mantap } \\
\text { untuk dapat menggunakan } \\
\text { kesempatan atau peluang yang } \\
\text { ada dalam perusahaan, sehingga } \\
\text { posisi atau kedudukan perusahaan } \\
\text { di pasar dapat dipertahankan dan } \\
\text { sekaligus ditingkatkan. }\end{array}$ & $\begin{array}{l}\text { Membahas strategi untuk } \\
\text { meningkatkan daya saing } \\
\text { perbankan }\end{array}$ \\
\hline
\end{tabular}

\subsection{Kompetensi}

Kompetensi menurut Spencer dan Spencer's (1993) dalam (Seong dan Ji, 2005:260) didefinisikan "sebagai karakteristik internal dari individu yang menghasilkan kinerja yang efektif dan unggul".

\subsection{Kinerja Karyawan}

Kinerja merupakan istilah yang berasal dari kata job performance atau actual performance (prestasi kerja atau prestasi sesungguhnya yang dicapai seseorang).Ukuran kinerja dapat dilihat dari sisi jumlah dan mutu tertentu, sesuai standar organisasi dan pelakunya. Bentuknya dapat bersifat tangible dan intangible, tergantung pada bentuk dan proses pelaksanaan pekerjaan itu sendiri, agar diperoleh hasil sesuai standar perusahaan atau organisasi maka kinerja perlu dikelola.

\subsection{Kualitas Pelayanan}

Kualitas pelayanan umum menurut Wyckof yang dikutip Tjiptono, yaitu sebagai berikut: "Kualitas pelayanan adalah tingkat keunggulan yang diharapkan dan pengendalian atas tingkat keunggulan tersebut untuk memenuhi keinginan pelanggan. Apabila jasa atau pelayanan yang diterima atau dirasakan (perceived service) sesuai dengan yang diharapkan, maka kualitas jasa atau pelayanan dipersepsikan baik dan memuaskan.Jika jasa atau pelayanan yang diterima melampaui harapan pelanggan, maka kualitas jasa atau pelayanan dipersepsikan sebagai kualitas yang ideal.Sebaliknya jika jasa atau pelayanan yang diterima lebih rendah daripada yang diharapkan, maka kualitas jasa atau pelayanan dipersepsikan buruk (Tjiptono, 2004:59).

\subsection{Manajemen Strategik}

Manajemen strategiatau manajemen strategik adalah keterampilan (seni), teknik, dan ilmu dalam merumuskan, mengimplementasikan, dan mengevaluasii serta mengawasi berbagai keputusan-keputusan fungsional sebuah organisasi (perusahaan bisnis ataupun non bisnis) yang selalu terpengaruhi oleh lingkungan eksternal dan internal dengan kondisi yang selalu berubah sehingga bisa memberi kemampuan pada perusahaan dalam pencapaian sasaran atau tujuan yang sudah ditetapkan.

\subsection{Teori SWOT}

Salah satu pakar SWOT Indonesia, Fredy Rangkuti (1997), “ Analisis SWOT adalah identifikasi berbagai faktor secara sistematis untuk merumuskan strategi perusahaan. Analisis ini didasarkan pada hubungan atau interaksi antar unsur internal, yaitu kekuatan dan kelemahan terhadap unsur-unsur eksternal yaitu peluang dan ancaman". 


\subsection{Kerangka Pemikiran}

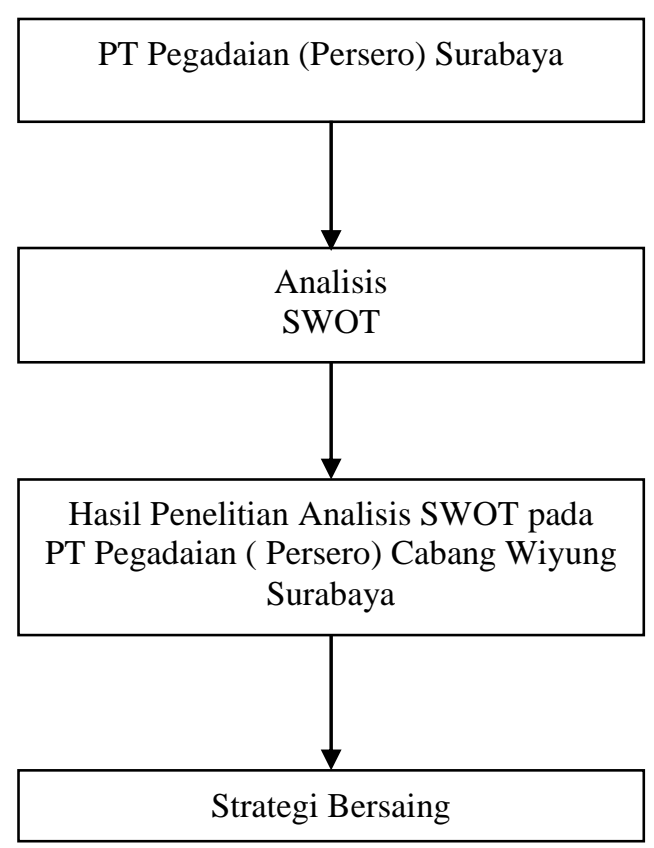

Gambar 1. Kerangka Pemikiran

\section{Metode Penelitian}

\subsection{Pendekatan Penelitian}

Penelitian yang dilakukan dalam penulisan ini adalah tergolong penelitian kualitatif, karena yang ingin diketahui adalah dalam menganalisis SWOT pada PT Pegadaian (persero) Cabang Wiyung Surabaya. Penelitian ini meneliti mengenai analisis SWOT dengan penelitian kualitatif, akan dicari ada tidaknya kekuatan, peluang, kelemahan dan ancaman yang terjadi pada perusahaan di PT Pegadaian (persero) Cabang Wiyung Surabaya.

\subsection{Tempat dan Waktu Penelitian}

Objek yang dijadikan penelitian adalah PT. Pegadaian (persero) Cabang Wiyung Surabaya yang beralamat di Raya Menganti No 411D Surabaya. Penelitian dilakukan dalam jangka waktu 1 bulan, diawali pada Bulan Januari 2016.

\subsection{Sumber dan Teknik Pengumpulan Data}

Subjek dan Informan dalam penelitian ini adalah orang yang memberikan informasi yang berkaitan dengan kebutuhan penelitian.Sumber data yang digunakan adalah data primer dan sekunder. Data primer adalah data yang yang diambil secara langsung oleh peneliti melalui observasi, wawancara, menyebarkan kuisioner. Dengan begitu peneliti juga bisa mendapatkan data-data yang diperlukan melalui pertanyaan yang ada di kuisioner tersebut, peneliti juga bisa mengamati responden secara langsung.Responden ini adalah karyawan yang kerjanya di posisi sebagai pimpinan cabang, penaksir, kasir pada PT. Pegadaian (persero)berjumlah 10 orang karyawan.

1. Survei

Teknik pengumpulan data dalam penelitian ini menggunakan 4 cara,yaitu :

2. Observasi

3. Wawancara

4. Kuisioner

\subsection{Validitas data}

Sebagai salah satu alat untuk formulasi strategi, analisis SWOT tidak dapat dipisahkan dari proses perencanaan strategik secara keseluruhan. Secara umum penyusunan rencana strategik melalui tiga tahapan, yaitu:

1. Tahap pengumpulan data

2. Tahap analisis

a. Matriks TOWS atau Matriks SWOT

b. Matriks Internal Eksternal 


\section{Tahap pengambilan keputusan}

\subsection{Teknik Analisa Data}

Dalam menganalisa data, peneliti menggunakan coding sebagai proses penganalisaan. Menurut Strauss dan Corbin terdapat 3 (tiga) macam/jenis proses analisis data (coding) yaitu Open Coding, Axial Coding, dan Selective Coding. Agar teori yang dibangun berdasarkan data itu tidak salah, ketiga macam coding tersebut harus dilakukan secara simultan dalam penelitian.

\section{Hasil Penelitian Dan Pembahasan \\ 4.1 Analisis Data}

Dalam mengidentifikasikan lingkungan internal maupun eksternal di PT Pegadaian (persero) Surabaya menjelaskan beberapa peluang yang dinilai keseluruhan untuk mencapai tujuan perusahaan. Meskipun beberapa perusahaan mempunyai tujuan yang sama tetapi strategi yang di gunakan berbeda-beda. Untuk mengetahui sejauh mana strategi yang di lakukan oleh PT Pegadaian (persero) Cabang Wiyung Surabaya berdasarkan analisis SWOT, dapat di lihat dalam perusahaan sebagai berikut.

1. Analisis faktor internal PT Pegadaian (persero) Cabang Wiyung Surabaya

Faktor-faktor internal PT Pegadaian (persero) Cabang Wiyung Surabaya meliputi strenght (kekuatan) dan weakness (kelemahan). Faktor internal meliputi memberikan kepercayaan kepada nasabah dengan baik agar tetap perusahaan semakin berkembang,

2. Analisis faktor eksternal PT Pegadaian (persero) Cabang Wiyung Surabaya

Faktor-faktor eksternal terdiri dari opportunities (peluang) dan threats (ancaman), faktor eksternal PT

Pegadaian (persero) Cabang Wiyung Surabaya pada mempertahankan produk-produk yang dimiliki pegadaian supaya tidak dapat mempengaruhi adanya pesaing pada usaha gadai yang sama.

Dari hasil analisa SWOT meliputi kekuatan, kelemahan, peluang serta ancaman pada PT Pegadaian (persero) Surabaya, yakni:

\subsubsection{Strenghts}

1. Produk jasa gadai dapat diperoleh dengan persyaratan yang sederhana

2. Bertambahnya jumlah kantor unit, sehingga dapat menjangkau seluruh wilayah

3. Perkembangan jumlah pelanggan terus meningkat dari tahun ketahun

4. Kinerja perusahaan selalu meningkat, menunjukkkan tingginya minat konsumen menggunakan jasa pegadaian

5. Promosi yang meningkat

\subsubsection{Weakness}

1. Memiliki misi sosial yaitu membantu program pemerintah dalam upaya meningkatkan kesejahteraan rakyat dan membantu usaha kecil dan mikro

2. Gedung kantor cabang banyak yang sudah tua

3. Sumber daya manusia yang masih harus dikembangkan

4. Pelayanan belum sesuai dengan standarisasi

\subsubsection{Opportunities}

1. Semakin banyaknya usaha kecil dan mikro yang membutuhkan modal

2. Jumlah penduduk yang semakin meningkatkan penyebaran penduduk yang semakin merata, sehingga memungkinkan untuk dibuka unit/outlet baru

3. Meningkatnya jumlah kebutuhan ekonomi rumah tangga

4. Perhatian pemerintah pada usaha kecil dan mikro yang semakin meningkat

5. PT Pegadaian (persero) cabang Wiyung surabaya yang memiliki pelanggan-pelanggan tetap

\subsubsection{Threats}

1. Banyak perusahaan serupa yang bermunculan menyamakan produk pegadaian

2. Munculnya kompetitor baru

3. Semakin meningkatnya tuntutan dari nasabah untuk pelayanan yang cepat dan memuaskan

4. Meningkatnya perkembangan perbankan syariah dan gadai syariah

5. Ketidakpuasan nasabah menjadi ancaman bagi perusahaan

\subsubsection{Matrik TOWS}

Alat yang digunakan untuk menyusun faktor-faktor strategis perusahaan adalah matriks SWOT . matriks ini dapat menggambarkan secara jelas bagaimana peluang dan ancaman eksternal yang dihadapi perusahaan 
dapat disesuaikan dengan kekuatan dan kelemahan yang dimilikinya. Matriks ini juga dapat menghasilkan empat kemungkinan alternatif strategis (Rangkuti, 1997:31). Matriks SWOT di PT Pegadaian (persero) Cabang Wiyung Surabaya.

Tabel 2. Matrik TOWS

\begin{tabular}{|c|c|c|}
\hline & Strength (S) & Weakness (W) \\
\hline Eksternal & $\begin{array}{l}\text { Bertambahnya jumlah } \\
\text { kantor unit } \\
\text { Lokasi yang strategis } \\
\text { SDM yang terlatih }\end{array}$ & $\begin{array}{l}\text { Keterbatasan agunan gadai } \\
\text { hanya pada barang bergerak } \\
\text { saja. } \\
\text { Penaksir tertipu oleh barang } \\
\text { emas palsu }\end{array}$ \\
\hline $\begin{array}{l}\text { Opportunities }(\mathrm{O}) \\
\text { Meningkatnya kebutuhan } \\
\text { ekonomi rumah tangga. } \\
\text { Brand image. } \\
\text { Dukungan pemerintah } \\
\text { dalam pendanaan } \\
\text { Merupakan pelopor usaha } \\
\text { gadai di indonesia. }\end{array}$ & $\begin{array}{c}\text { SO Strategi } \\
\text { Peningkatan kualitas } \\
\text { pelayanan untuk mencapai } \\
\text { loyalitas konsumen } \\
\text { terhadap jasa pegadaian } \\
\text { Peningkatan kualitas SDM } \\
\text { yang dimiliki perusahaan } \\
\text { Mengadakan promosi } \\
\text { melalui penyuluhan ke } \\
\text { masyarakat untuk } \\
\text { memasarkan produk }\end{array}$ & $\begin{array}{c}\text { WO Strategi } \\
\text { Melakukan kerjasama } \\
\text { dengan berbagai pihak } \\
\text { Merekrut karyawan secara } \\
\text { lebih selektif } \\
\text { Memperkenalkan produk } \\
\text { pegadaian }\end{array}$ \\
\hline $\begin{array}{l}\text { Threats }(\mathrm{T}) \\
\text { Munculnya perusahaan } \\
\text { yang memproduksi jasa } \\
\text { gadai yang sejenis. } \\
\text { Meningkatnya } \\
\text { perkembangan perbankan } \\
\text { syariah dalam gadai. } \\
\text { Perampokan sering terjadi. }\end{array}$ & $\begin{array}{c}\text { ST Strategi } \\
\text { Menjaga kualitas layanan } \\
\text { dan meningkatkan empati } \\
\text { kepada nasabah. } \\
\text { Melakukan promosi sebaik } \\
\text { dan semenarik mungkin } \\
\text { guna menarik calon } \\
\text { pelanggan. } \\
\text { Penjagaan yang lebih ketat }\end{array}$ & $\begin{array}{c}\text { WT Strategi } \\
\text { Mengembangkan kantor unit } \\
\text { cabang pembantu agar dapat } \\
\text { memperkenalkan produk } \\
\text { pegadaian kepada } \\
\text { masyarakat sekitar. } \\
\text { Meningkatkan kualitas jasa } \\
\text { yang dimiliki. }\end{array}$ \\
\hline
\end{tabular}

\subsection{Analisis EFFAS dan IFFAS}

Setelah faktor-faktor strategi internal dan eksternal suatu perusahaan diidentifikasi, suatu tabel IFAS dan EFAS disusun untuk merumuskan faktor-faktor strategi internal tersebut dalam kerangka Strenght and Weakness pada perusahaan PT Pegadaian (persero) Cabang Wiyung Surabaya. Dari hasil pengamatan kuisioner pada responden yang dipilih, kemudian dengan perhitungan seperti pada table berikut ini untuk menentukan nilai bobot,rating dan skornya.

Tabel 3. Analisis Strenghts

\begin{tabular}{lllc}
\hline \multicolumn{1}{c}{ Faktor Internal Strategi } & Berat & Penilaian & Tertimbang Skor \\
\hline $\begin{array}{l}\text { Persyaratan menggadaikan } \\
\text { yang sederhana }\end{array}$ & Strenghts & & \\
$\begin{array}{l}\text { Bertambahnya jumlah kantor } \\
\text { unit }\end{array}$ & 0,25 & 3 & 0,75 \\
$\begin{array}{l}\text { Perkembangan jumlah } \\
\text { pelanggan }\end{array}$ & 0,30 & 3 & 0,9 \\
$\begin{array}{l}\text { Kinerja perusahaan selalu } \\
\text { meningkat }\end{array}$ & 0,20 & 2 & 0,20 \\
$\quad$ Total Score & 1,00 & & 0,4 \\
\hline
\end{tabular}


Tabel 4. Weakness

\begin{tabular}{llll}
\hline \multicolumn{1}{c}{ Faktor Internal Strategi } & Berat & Penilaian & Tertimbang Skor \\
\hline & Weakness & & \\
\hline $\begin{array}{l}\text { Gedung kantor cabang banyak } \\
\text { yang sudah tua }\end{array}$ & 0,11 & 1 & 0,11 \\
$\begin{array}{l}\text { Sumber daya manusia yang } \\
\text { masih harus dikembangkan }\end{array}$ & 0,14 & 2 & 0,28 \\
$\begin{array}{l}\text { Pelayanan belum sesuai dengan } \\
\text { standarisasi }\end{array}$ & 0,20 & 3 & 0,6 \\
$\begin{array}{l}\text { Memiliki misi sosial } \\
\quad \text { Total Score }\end{array}$ & 0,30 & 3 & 0,9 \\
& 1,00 & & 2,39 \\
\hline
\end{tabular}

Tabel 5. Opportunities

\begin{tabular}{lccc}
\hline \multicolumn{1}{c}{ Faktor Eksternal Strategi } & Berat & Penilaian & Tertimbang Skor \\
\hline & Opportunities & & \\
\hline $\begin{array}{l}\text { Semakin banyaknya usaha kecil } \\
\text { dan mikro yang membutuhkan } \\
\text { modal }\end{array}$ & 0,14 & 3 & 0,42 \\
$\begin{array}{l}\text { Jumlah penduduk yang semakin } \\
\text { meningkatdan penyebaran } \\
\text { penduduk yang semakin merata }\end{array}$ & 0,25 & 3 & 0,75 \\
$\begin{array}{l}\text { Meningkatnya jumlah } \\
\text { kebutuhan ekonomi rumah } \\
\text { tangga }\end{array}$ & 0,26 & 2 & 0,78 \\
$\begin{array}{l}\text { PT Pegadaian (persero) cabang } \\
\begin{array}{l}\text { Wiyung surabaya yang } \\
\text { memiliki pelanggan-pelanggan } \\
\text { tetap. }\end{array}\end{array}$ & 0,15 & 2 & 0,3 \\
\hline$\quad$ Total Score & 1,00 & & 2,45 \\
\hline
\end{tabular}

Tabel 6. Threats

\begin{tabular}{lccc}
\hline \multicolumn{1}{c}{ Faktor Eksternal Strategi } & Berat & Penilaian & Tertimbang Skor \\
\hline $\begin{array}{l}\text { Banyak perusahaan serupa yang } \\
\text { bermunculan menyamakan } \\
\text { produk pegadaian }\end{array}$ & 0,20 & 3 & 0,6 \\
$\begin{array}{l}\text { Munculnya kompetitor baru. } \\
\begin{array}{l}\text { Meningkatnya perkembangan } \\
\text { perbankansyariahdan gadai } \\
\text { syariah. }\end{array}\end{array}$ & 0,23 & 3 & 0,69 \\
$\begin{array}{l}\text { Ketidak puasan nasabah } \\
\text { menjadi ancaman bagi }\end{array}$ & 0,14 & 2 & 0,28 \\
perusahaan & 0,17 & 2 & 0,34 \\
$\quad$ Total Score & 1,00 & & 2,66 \\
\hline
\end{tabular}

Skor yang telah disepakati :

1) Kategori Berat
$0,01-0,15=$ Kurang Penting
$0,16-0,30=$ Cukup Penting
$0,31-0,45=$ Sangat Penting

2) Kategori Penilaian
Angka 3
$=$ Sangat Tinggi
Angka 2
$=$ Cukup Tinggi
Angka 1
$=$ Kurang Tinggi 


\subsection{Pembahasan Hasil Penelitian}

Matriks SWOT disusun berdasarkan hasil identifikasi faktor internal (kekuatan dan kelemahan) dan faktor eksternal (peluang dan ancaman) perusahaan yang telah diolah. Pemanduan faktor internal maupun eksternal perusahaan dalam matriks SWOT akan menghasilkan beberapa alternatif strategis yang dapat digunakan oleh perusahaan. Beberapa alternatif strategis yang dihasilkan dalam matriks SWOT di PT Pegadaian(persero) Cabang Wiyung Surabaya maka untuk formulasi strategi yang dipilih yaitu:

1. Strategi kekuatan-peluang (SO)

Strategi yang dihasilkan pada kombinasi ini adalah memanfaatkan kekuatan atas peluang yang telah di identifikasi.

a. Perkembangan jaman memberikan peluang yang tinggi kepada perusahaan untuk menambah calon nasabah. Letak PT Pegadaian(persero) Cabang Wiyung Surabaya yang berada di pemukiman padat penduduk membuat bertambahnya jumlah nasabah untuk dapat memperkenalkan produk-produk.

b. Peningkatan terhadap sistem kinerja karyawan terus dilakukan untuk menambah kepuasan pelanggan, sehingga saat ada nasabah baru perusahaan diharapkan dapat memeberikan ekspektasi lebih kepada pelanggan

2. Strategi kekuatan-ancaman (ST)

Dalam analisa ancaman ditemukan kebutuhan untuk mengatasinya. Strategi ini mencoba mencari kekuatan yang dimiliki perusahaan yang dapat mengurangi atau menangkal ancaman tersebut.Memperbaiki sistem, meningkatkan layout dan kinerja karyawan serta keamanan yang lebih diperketat, hal tersebut dimaksudkan agar kepuasan dan kepercayaan pelanggan meningkat dan loyalitas terhadap perusahaan bertambah

3. Strategi kelemahan-peluang (WO)

Strategi ini merupakan alternatif strategi untuk meminimalkan kelemahan yang dimiliki perusahaan dengan memanfaatkan peluang yang ada secara maksimal, strategi yang dapat di gunakan perusahaan adalah. Menambah jasa yang di tawarkan bila sebelumnya terbatas pada barang bergerak, maka sekarang bisa ditambah dengan agunan tidak bergerak karena jasa yang ditawarkan lebih bervariasi.

4. Strategi kelemahan-ancaman (WT)

Dalam situasi menghadapi ancaman dan sekaligus kelemahan internal, strategi yang umumnya dilakukan adalah "keluar" dari situasi yang terjepit tersebut. Strategi yang yang bisa diterapkan PT Pegadaian(persero)Cabang Wiyung Surabaya dengan meminimalkan kelemahan yang dimiliki untuk menghindari ancaman yang dihadapi adalah menambahkan produk-produk yang ditawarkan agar mampu bersaing dan bertahan dalam persaingan setidaknya perusahaan harus mampu menyamakan kedudukan atau tidak lebih baik dari pesaing

\subsubsection{Diagram Analisis SWOT}

Selanjutnya dari hasil analisa dengan menggunakan matrik IFAS dan EFAS akan dianalisis dengan menggunakan diagram analisis SWOT untuk mendapatkan gambaran akhir kedudukan produk PT Pegadaian (persero) Cabang Wiyung Surabaya dengan produk-produk sejenis dari perusahaan lain.

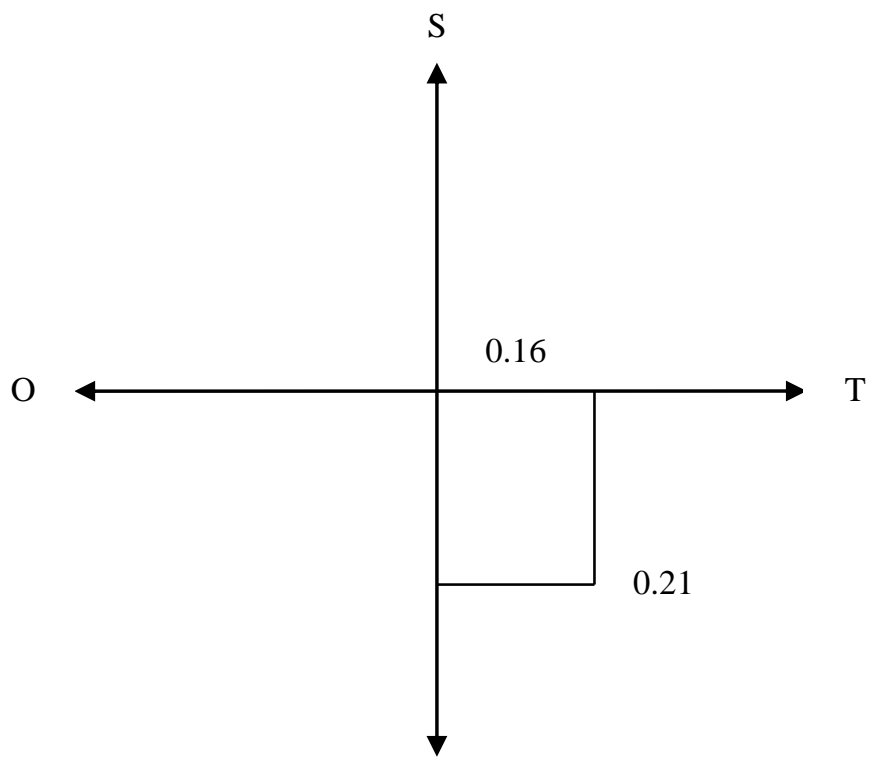

Gambar 2. Diagram Analisis SWOT 
Total Skor Strength

$$
=2,55
$$

Total Skor Weakness

$=2,39$

$=2,45$

$=2,66$

$=2,55-2,39=0,16$

$=2,06-2,66=-0,21$

Strength - Weakness

Opportunities - Threats

\subsubsection{Perumusan Strategi Bersaing}

Berdasarkan hasil analisis dengan menggunakan matrik SWOT dari beberapa faktor internal, berupa kekuatan dan kelemahan, serta faktor eksternal berupa peluang dan ancaman untuk menentukan strategi kompetitif produk bagi PT Pegadaian(peersero) Cabang Wiyung Surabaya), yaitu dengan melakukan :

1. PT Pegadaian (persero) Surabaya yang sudah dikenal masyarakat akan memberikan nilai positif bagi perusahaan sehingga konsumen-konsumen tetap setia pada PT Pegadaian (persero) Surabaya

2. Perusahaan dituntut untuk semakin meningkatkan kinerja perusahaan dalam pasar yang semakin kompetitif dalam rangka menciptakan nilai tambah baik bagi pemegang saham dan mengakomodasi pihakpihak yang berkepentingan dengan perusahaan.

3. Dengan adanya kebutuhan masyarakat yang semakin beraneka ragam, PT. Pegadaian (persero) demi memenuhi segala kebutuhan tersebut maka membuka sebuah Pegadaian Syariah. Dengan begitu para pelanggan bisa merasa lebih aman, nyaman dan terjaga.

Implementasi strategi pengembangan PT Pegadaian (persero) Cabang Wiyung Surabaya memiliki beberapa implikasi kebijakan yang harus dilakukan, meliputi:

1. Pengelolaan SDM

Sumber daya manusia sangat penting bagi perusahaan karena SDM merupakan jembatan bagi konsumen untuk menjadi loyal kepada perusahaan, peningkatan kualitas SDM dapat dilakukan dengan cara mengadakan pelatihan, komunikasi dan kerja sama antar karyawan atau memberi peraturan mengenai bagaimaan seorang pegawai harus bersikap kepada konsumen.

2. Promosi

Pengelolaan dapat meningkatkan promosi yang lebih gencar, misal dengan cara door to door pada suatu perkumpulan dengan terjun langsung ke masyarakat menengah ke bawah, mengadakan bazar, memberikan penyuluhan dan informasi secara face to face akan membuat konsumen lebih mengenal.paham dan mengerti mengenai jasa yang ditawarkan.

\section{Penutup}

\subsection{Kesimpulan}

Setelah dilakukan analisis terhadap perusahaan dengan menggunakan analisis SWOT, dapat diketahui bahwa perusahaan PT Pegadaian (persero) Cabang Wiyung Surabaya pada saat ini berada dalam kondisi baik namun menghadapi sejumlah tantangan berat. Dengan strategi yang hanya memfokuskan pada perusahaan yang berlokasi di cabang wiyung surabaya, perusahaan akan mengalami kesulitan dalam meningkatkan kinerjanya. Hasil penelitian menunjukkan bahwa strategi baru yang harus dilakukan perusahaan adalah strategi kompetitif dalam produk dan pelayanan. Strategi untuk menciptakan produk baru dan meningkatkan pelayanan dengan mempertahankan kinerja karyawan agar lebih baik lagi menjadikan PT. Pegadaian (persero) cabang wiyung surabaya lebih berkembang dan sukses dengan lebih banyak pelanggan setia.

Strategi PT Pegadaian (persero) Cabang Wiyung Surabaya dalam upaya memberikan pelayanan yang berkualitas, mempertahankan loyalitas nasabah, dan meningkatkan jumlah nasabah ditinjau dari faktor ekstern adalah:

1. Pemanfaatan kesempatan dengan menyampaikan promosi dengan sebaik mungkin tentang produk jasa yang ditawarkan, sehingga bisa menarik perhatian serta mengumpulkan calon konsumen yang banyak

2. Menyusun action plan, yaitu mengusahakan sumber pendanaan yang relative murah dengan cara mengusulkan penambahan modal, memperluas jangkauan pelayanan dengan pembukaan outlet di daerah potensial, mengintensifkan program pemasaran, pelatihan dan pengembangan SDM, meningkatkan kualitas pelayanan kepada nasabah, menciptakan produk layanan baru sesuai kebutuhan masyarakat,dan mengusahakan pembiayaan untuk memperbaiki sarana dan prasarana yang ada.

\subsection{Saran}

Setelah penulis mempelajari keadaan yang terjadi pada perusahaan,penulis menyarankan agar perusahaan PT Pegadaian (persero) Cabang Wiyung Surabaya memperhatikan hal-hal sebagai berikut:

1. PT Pegadaian (persero) Cabang Wiyung Surabaya disarankan untuk selalu menyiapkan karyawandan petugas yang profesional. Petugas harus memiliki ketrampilan dan pengetahuan yang memadai dalam bidang telekomunikasi, bersikap sopan dalam melayani pelanggan, dan cepat tanggap akan apa yang diinginkan oleh konsumen /pelanggan. 
2. Pembukaan unit-unit pegadaian cabang Wiyung yang baru untukmemperluasdaerahpemasaran

3. PT Pegadaian (persero) Cabang Wiyung Surabaya harus memperbanyak diversifikasi produk jasa untuk mendapatkan pelanggan yang lebih banyak.

\section{Daftar Pustaka}

Amirullah, 2015.Manajemen Strategi Teori-Konsep-Kinerja, Edisi Pertama, Jakarta.Penerbit Mitra Wacana Media.

DR. A.A. Anwar Prabu Mangkunegara,MSi, 2014. Evaluasi Kinerja SDM Cetakan Ketujuh. Bandung. Unit Penerbit Refika Aditama

Dr Suwandi,M.Si.\&Dr. Basrowi, M.Pd, 2008. Memahami Penelitian Kualitatif. Cetakan Pertama,Desember 2008, Jakarta. Rineka Cipta

Isoraite, Margarita. 2008. The Balance Scorecard Method: From Theory to Practice. Intelectual Economics, 1(3): 18-28.

Kaplan, Robert S. and David P. Norton. 1996. Strategy Map: Converting Intangible Assets into Tangible Outcomes. Boston: Harvard Business School Press.

Malmi, Temuu. 2001. Balanced Scorecards in Finnish Companies: A Research Note. Management Accounting Research, 12: 207-220.

Moleong, Lexy J. 2007. Metodologi Penelitian Kualitatif. Bandung: Remaja Rosda Karya.

Rangkuti, Freddy, 2015. Analisis SWOT, Cetakan Keduapuluh, Jakarta. PT. Gramedia Pustaka Umum. 